\title{
SALUD OCUPACIONAL: HISTORIA Y RETOS DEL FUTURO
}

\author{
OCCUPATIONAL HEALTH: \\ HISTORY AND FUTURE CHALLENGES
}

\author{
María del Carmen Gastañaga ${ }^{1, a}$
}

La actividad laboral del ser humano ha permitido transformar el mundo pero, al mismo tiempo, ha generado riesgos y enfermedades que han sido reconocidas desde muy antiguo. Galeno describió las intoxicaciones de los mineros de Chipre; durante el renacimiento, Georg Agricola (1494-1555) realizó una primera división entre enfermedades laborales crónicas y agudas; Paracelso, a mediados del siglo XVI, escribió el primer tratado de enfermedades de los mineros; y en 1733 Bernardino Ramazzini, escribió el De morbis artificum diatriba (discurso sobre las enfermedades de los trabajadores) con el cual se incorpora la salud ocupacional como una rama de la medicina.

Desde entonces, la salud ocupacional ha tenido un enorme desarrollo, la revolución industrial incorporó desde el campo a ingentes masas de trabajadores hacia las fábricas, en condiciones muchas veces infrahumanas, lo que dio lugar a una amplia crítica social pero también al desarrollo de estudios e investigaciones que establecieron la relación directa entre diversas ocupaciones y la enfermedad. En Perú, la primera mención a las enfermedades ocupacionales es del periodo colonial cuando se hace referencia a los indígenas obligados a laborar en las minas de donde, por intoxicación, pocos sobrevivían.

Sin embargo, la era científica de la salud ocupacional tendría que esperar hasta el periodo republicano cuando se encarga, en 1926, a la entonces Dirección de Salubridad del Ministerio de Fomento (aún no existía el Ministerio de Salud) el control e inspección de higiene de todos los centros de trabajo. En 1957 se realizó el Primer Seminario Nacional de Salud Ocupacional, y el director de aquel entonces Dr. Frederick J. Vintinner, quien durante la inauguración del evento dijo: La Salud Ocupacional ha sido definida como la ciencia y arte de preservar la salud mediante el reconocimiento, evaluación y control de las causas de medio ambiente, que originan las enfermedades en la industria... Es un axioma bien conocido que el trabajador enfermo es una carga para sí mismo, para la familia, para la comunidad y el país. El programa de Salud Ocupacional en el Perú ha sido desarrollado como un programa integral dirigido hacia la conservación y promoción de la salud del trabajador...

Hablar de Salud Ocupacional en Perú, es hablar del Instituto de Salud Ocupacional, que inicia su historia con la creación del Departamento Nacional de Higiene Industrial por Decreto Supremo el 5 de agosto de 1940, el cual, posteriormente, se transformará en el Instituto de Salud Ocupacional. El 12 de marzo de 1947, fue promulgada la Ley 10833 que creaba fondos para el referido Departamento, además de especificar sus funciones.

El Instituto de Salud Ocupacional (ISO) financia sus actividades con fondos propios que son recaudados por el Ministerio de Hacienda, de la contribución del 1,8\% de las empresas mineras y conexas. El ISO, continuó desarrollando los objetivos fundamentales de contribuir a mantener y promover el estado físico, mental y social de los trabajadores en todos los campos de trabajo, prestando servicios de preferencia en la minería; sin embargo, también dentro de sus posibilidades, a la industria manufacturera y a las actividades agropecuarias; por ello, contó con un acervo documentario de apoyo de las diferentes disciplinas tanto en castellano como en otros idiomas (inglés, alemán, francés, entre otros). A partir del año 1963 queda sin efecto la contribución monetaria de minería.

El Instituto contó con un gran número de estudios evaluativos de salud ocupacional; estudios que correspondían a minas, fundiciones, fábricas de harina de pescado, de tejidos, de pinturas, y de otras

\footnotetext{
Centro Nacional de Salud Ocupacional y Protección del Ambiente para la Salud; Instituto Nacional de Salud. Lima, Perú.

a Médico especialista en Gestión y Auditorías Ambientales
} 
entidades industriales; por ello, el personal publicó artículos sobre temas de la especialidad en los boletines y revistas del Instituto de Salud Ocupacional, entre otros. Las revistas se encuentran actualmente en la Biblioteca del Centro Nacional de Salud Ocupacional y Protección del Ambiente para la Salud del Instituto Nacional de Salud (INS); en su género, fueron de las pocas en Latinoamérica y únicas en el país; tuvieron una distribución nacional e internacional desde 1956.

El Instituto de Salud Ocupacional fue el primer centro de entrenamiento de la especialidad para higienistas industriales de Latinoamérica ${ }^{(1)}$; durante el entrenamiento impartido se ha buscado unificar criterios en esta disciplina, convencidos de la importancia que esta medida tiene para una efectiva solución de los problemas de salud ocasionados por acción directa de los ambientes insalubres de trabajo.

El 2 de mayo de 1958 se inauguró la Unidad Regional del Sur del Instituto de Salud Ocupacional, con sede en la ciudad de Arequipa, siendo su labor principal la prevención de enfermedades profesionales en la minería de siete departamentos que forman esta unidad: Ayacucho, Apurímac, Cusco, Puno, Arequipa, Moquegua y Tacna. Posteriormente, fueron inauguradas las Unidades Regionales de La Oroya y Trujillo.

En enero de 1969, el ISO es incorporado al INS ${ }^{(2)}$; luego de varios cambios situacionales (reconocimiento como Instituto Nacional de Salud Ocupacional en 1985; y final reincorporación al INS en 2002) adopta finalmente la denominación de Centro Nacional de Salud Ocupacional y Protección del Ambiente para la Salud (CENSOPAS).

Esto muestra que en toda la historia del desarrollo de la Salud Ocupacional en el Perú, exceptuando los primeros años, se ha tenido altibajos; en parte, por no estar integrada en una política de Estado y por no ser considerada entre las prioridades de salud. Si bien algunos gobiernos han creado mecanismos legales internos así como mediante suscripción de convenios y directivas vinculantes, aún no es objeto efectivo de derecho. La inadecuada atención de la salud de los trabajadores imposibilita nuestro desarrollo socioeconómico y perjudica cada vez a más personas. Por eso, es prioritario no solo tomar conciencia sino actuar pronto, e incentivar el desarrollo de programas específicos de salud ocupacional y también fortalecer los existentes.

Se requiere un cambio en la cultura empresarial y procurar, con los directivos de las organizaciones, desarrollar la salud ocupacional como una herramienta de inversión que mejore la productividad y rentabilidad. También se debe buscar modificar el concepto de salud ocupacional como una norma, para convertirla en una acción que el Estado hace por el bien del trabajador.
Al ser el problema de la salud ocupacional un problema global, es importante señalar un párrafo publicado en la revista de la OIT por el Día Mundial de la Seguridad y la Salud en el Trabajo el 28 de abril de 2012, y cuyo lema es "Promover la seguridad y la salud en una economía verde": El siglo XXI se enfrenta a dos desafíos muy concretos. El primero es evitar el peligroso cambio climático y el deterioro de los recursos naturales que podrían socavar gravemente la calidad de vida de las generaciones presentes y futuras. El segundo, es asegurar que el desarrollo sostenible se apoye en tres dimensiones fundamentales: el crecimiento económico; la equidad social, y la protección del medio ambiente. La "economía verde» se ha convertido en un emblema de una economía y una sociedad más sostenibles, decididas a conservar el medio ambiente para las futuras generaciones y a garantizar a todas las personas y a todos los países unas condiciones más equitativas e incluyentes. Como consecuencia, el avance hacia una "economía verde» que cree "empleos verdes» $y$ "ecologice " las industrias, los procesos de producción y los empleos actuales, se ha convertido en un elemento clave para lograr un desarrollo social y económico medioambientalmente sostenible. En este contexto, la inclusión social, el desarrollo social y la protección del medio ambiente deberian estar estrechamente vinculados con unos lugares de trabajo más seguros y saludables, y con el trabajo decente para todos ${ }^{(3)}$.

Para concluir, debemos mencionar que es evidente en nuestro país el crecimiento económico sostenido, teniendo como soporte a la población laboral cuya salud debe ser vista como una necesidad para garantizar ese crecimiento, se requiere para ello la investigación y la generación de evidencias para la toma de decisiones de control y prevención de problemas en este campo.

Esperamos que las contribuciones presentadas en este número de la RPMESP sirvan como impulso para fomentar la investigación en salud ocupacional y tomar medidas concretas para mejorar las condiciones de trabajo y garantizar la salud de los millones de trabajadores expuestos a riesgos ocupacionales.

\section{REFERENCIAS BIBLIOGRÁFICAS}

1. Editorial. Revista del Instituto de Salud Ocupacional. 1964;IX(3-4).

2. Academia Peruana de Salud. XXXIX Foro "Salud $y$ Desarrollo". Historia de la salud en el Perú. Revista de la Academia Peruana de Salud. 2007;14(1):66-80.

3. Organización Internacional del Trabajo (OIT). Programa de Seguridad y Salud en el Trabajo y Medio Ambiente (Safe Work). 1ra edición. Ginebra: OIT; 2012. 